\title{
Changes in Scholastic Achievement and Intelligence of Indian Children Enrolled in a Foster Placement Program
}

\author{
Linda Ouida Willson \\ Brigham Young University - Provo
}

Follow this and additional works at: https://scholarsarchive.byu.edu/etd

Part of the Indigenous Studies Commons, Mormon Studies Commons, and the Psychology Commons

\section{BYU ScholarsArchive Citation}

Willson, Linda Ouida, "Changes in Scholastic Achievement and Intelligence of Indian Children Enrolled in a Foster Placement Program" (1973). Theses and Dissertations. 5216.

https://scholarsarchive.byu.edu/etd/5216

This Thesis is brought to you for free and open access by BYU ScholarsArchive. It has been accepted for inclusion in Theses and Dissertations by an authorized administrator of BYU ScholarsArchive. For more information, please contact scholarsarchive@byu.edu, ellen_amatangelo@byu.edu. 
$130.0 x$

CHANGES IN SCHOLASTIC ACHIEVEMENT AND INTELLIGENCE

OF INDIAN CHILDREN ENROLLED IN A

FOSTER PLACEMENT PROGRAM

\author{
A Thesis \\ Presented to the \\ Department of Psychology \\ Brigham Young University
}

In Partial Fulfillment

Of the Requirements for the Degree

Master of Science

by

Linda Ouida Willson

April 1973 
This thesis, by Linda Ouida Willson, is accepted in 1ts present form by the Department of Psychology of Brigham Young University as satisfying the thesis requirement for the degree of Master of Science.

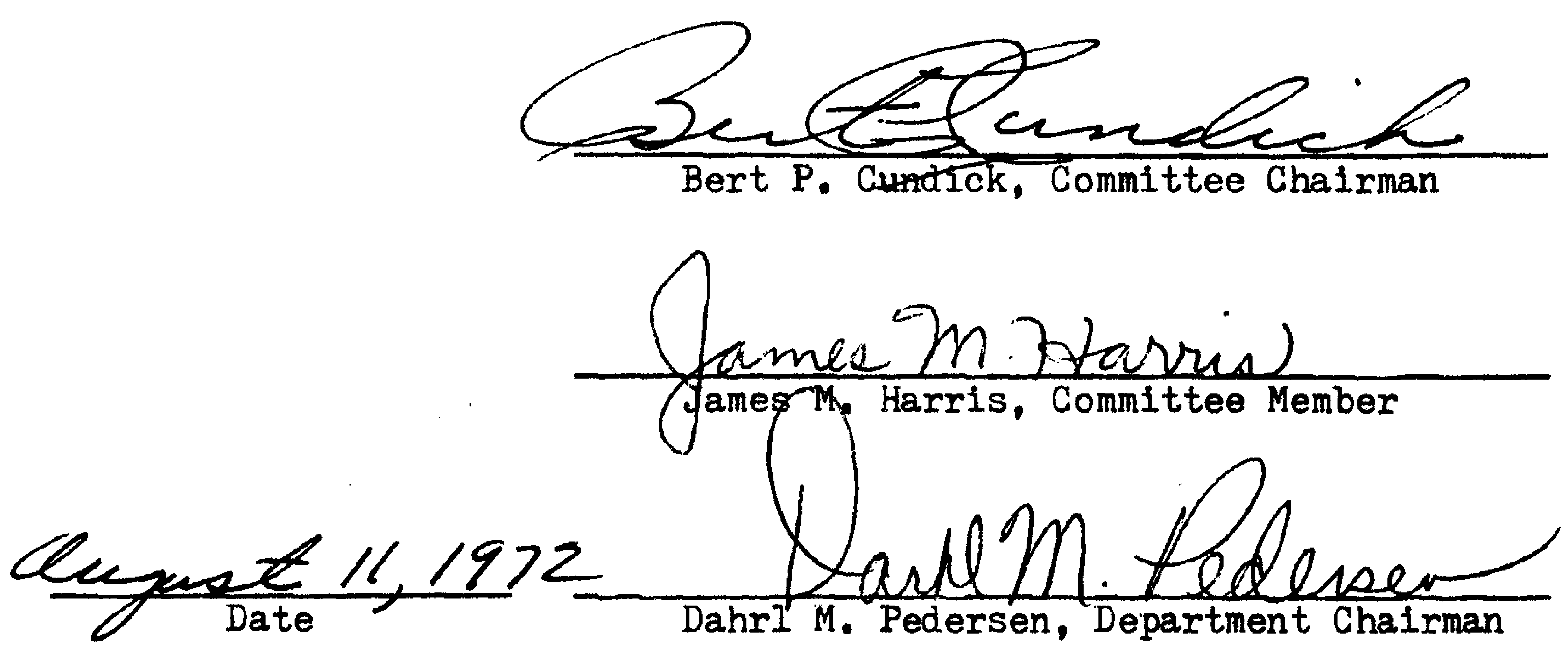




\section{ACKNOWLEDGMENTS}

I wish to express my sincere appreciaton to $\mathrm{Dr}$. Bert $\mathrm{P}$. Cundick for his idea for this thesis and for his continued assistance, guidance, and support throughout the project. I am also especially grateful to Doug Gottfredson for his invaluable help with the statistical analysis, and to Dr. James M. Harris for his suggestions and assistance. Special thanks go to the LDS Social Services personnel, and particularly to Brother Glen Van Wagenen, for permission to do the study and assistance with it. Also, I wish to thank Alpine, Davis, Granite, Jordan, Murray, Nebo, Provo, Salt Lake City, and Tooele school districts for allowing me to use their records.

This thesis could not have become a reality without the patient encouragement and support of parents, friends, and roommates. I am especially grateful for their help and for just putting up with me during the last few weeks of this project. 
TABLE OF CONTENTS

Page

LIST OF TABLES . . . . . . . . . . . . . . . . . v v

LIST OF FIGURES . . . . . . . . . . . . . . . . . . vil

CHAPTER

1 INTRODUCTION AND STATEMENT OF THE PROBLEM . . . 1

2 REVIEW OF THE LITERATURE . . . . . . . . 4

Intelligence Tests

Achievement Tests

History of Indian Education

IDS Placement Program

Purposes of this Study

3

METHOD . . . . . . . . . . . . .

21

Subjects

Measures

Procedures

Data Treatment

Design

4

RESULIS . . . . . . . . . . . . 28

Mathematical Achievement

Reading Achievement

Language Achievement

Verbal Intelligence

Total Intelligence

Covariates and Other Factors

5

DISCUSSION .............. . . 49

Scholastic Achievement

Intelligence

Limitations of this Study

Suggestions for Further Research

6

SUMMARY AND CONCLUSIONS . . . . . . . . . 56

REFERENCES . . . . . . . . . . . . . . . . 59 


\section{LIST OF TABLES}

Table

Page

1 Math Achievement Mean Deviation Scores as a Function of Sex and Year in Program . . . . . . . .

2 Effects of Sex and Years in Program on Math Achievement ...................

3 Test on Math Achievement Mean Scores for Years in Program (Newman-Keuls) . . . . . . 30

4 Reading Achievement Mean Deviation Scores as a Function of Sex and Year in Program . . . . .

5 Effects of Sex and Years in Program on Reading Achievement . . . . . . . . . 32

6 Language Achievement Mean Deviation Scores as a Function of Sex and Year in Program . . . . . 32

7 Effects of Sex and Years in Program on Language Achievement . . . . . . . . . . . .

8 Verbal IQ Mean Scores as a Function of Sex and Year in Program. . . . . . . . . . .

Effects of Sex and Years in Program on Verbal IQ

Test on Verbal Intelligence Mean Scores for Years in Program (Newman-Keuls) . . . . . . 36

11 Nonverbal IQ Mean Scores as a Function of Sex and Year in Program . . . . . . . . . . 37

12 Effects of Sex and Years in Program on Nonverbal IQ . . . . . . . . . . . . . 37

13 Test on Nonverbal Intelligence Mean Scores for Years in Program (NewmanKeuls)

14 Total IQ Mean Scores as a Function of Sex and Year in Program............. 40 
LIST OF TABLES

(Continued)

Page

15 Effects of Sex and Years in Program on Total IQ . . . . . . . . . . . . . 4 40

16 Effects of Sex and Years in Program on Math Achlevement with Year of Placement

as a Covariate . . . . . . . . . . . . .

17 Effects of Sex and Years in Program on Math Achievement with Beginning Grade as a Covariate .............. . . 42

18 Effects of Sex and Years in Program on Math Achievement with Achievement Test as a Covariate .............. 42

19 Covariate Effect on Reading Achievement Scores ................ . . 4 43

20 Effects of Sex and Years in Program on Language Achievement with Year of Placement as a Covariate . . . . . . . . . 44

21 Effects of Sex and Years in Program on Language Achievement with Beginning Grade as a Covariate . . . . . . . . . . . .

Effects of Sex and Years in Program on Language Achievement with Beginning Age as a Covariate .. . . . . . . . . . . 45

23 Effects of Sex and Years in Program on Language Achievement with Achievement Test as a Covariate .............. 46 Covariate Effect on Verbal IQ Scores ........ 46 Covariate Effect on Nonverbal IQ Scores . . . . . 47 26 Covarlate Effect on Total IQ Scores . . . . . . 48 


\section{LIST OF FIGURES}

$\begin{array}{ll}\text { Figure } & \text { Page }\end{array}$

1 Mean IQ Scores By Year in Program . . . . . . . 35

vii 


\title{
CHAPTER 1
}

\section{INTRODUCTION AND STATEMENT}

OF THE PROBLEM

\begin{abstract}
"National disgrace... one of the saddest stories in our nation's history (p. 25)," comments Senator Walter F. Mondale (Indian education, 1970).

"...the most disadvantaged minority (p. 15)," asserts McGeorge Bundy, Ford Foundation executive (The angry American,
\end{abstract} 1970).

"The most terrible life known to any group in this country today (p. 113)," declares a popular magazine (Erickson, 1970). These and other recent comments in both technical journals and popular magazines indicate a growing public and professional concern over the problems and plights of American Indians today. The Indians themselves are also increasingly aware of their disadvantaged situation and are searching for a better life. With this awareness, and the introduction of the mass media, improved transportation, increasing education, a high birth rate, and continuing poverty on many of the reservations, a large number of Indians have moved from reservations into the cities seeking equal opportunities with their white peers. A small but vocal "red movement" has developed recently among discontented and unhappy Indians who have sought to publicize that the opportunities for Indians both on and off the reservations are not equal to white opportunities. The public 
and Indian concerns and claims of disadvantaged status are justified as the following statistics point out,

1. The mortality rate of Indian babies is the highest in the United States.

2. The suicide rate among Indian teenagers is three times the national average.

3. The Iife expectancy of an Indian is about seven years less than the white life expectancy.

4. The une ployment rate is almost 10 times the national average among Indians. 5. The average income of Indians is $\$ 1,500$ per year, which is less than the average for any other minority group. 6. The educational level attained by Indians is less than half the norm of the general population, and the school dropout rate is double that of the total population. Illiteracy is the highest of any minority group (Edington, 1969; Erickson, 1970; Tunley, 1970).

This last statistic perhaps contains the key to the other problems faced by this minority group today--education. Education in the American culture is traditionally a major prerequisite for success, financial well being, acceptance, and equal opportunity, particularly in employment. Also, as education improves, at least up to a certain point, health improves and infant mortality decreases. However, education of Indians in the United States has historically been, and generally still is today, weak, inadequate, and ineffective as manifest in low achievement, high dropout rates, and little apparent effect on life style. These failures of education have many causes which should be clarified and understood before necessary changes can be instituted to ensure that Indian children can receive equal opportunities in school and life.

In the past few years various programs have been instituted by different agencies seeking to better the Indian's status and opportunity through better education. The particular educational 
program of interest in this study is the Indian Placement Program of the Church of Jesus Christ of Latter-day Saints. The basis of this Program is to place children who can take good advantage of educational opportunities in a supportive white foster home situation during the school year so they can attend regular public schools. The primary goals of this Program are twofold: (1) give the children a better school setting and a home with the environment, attitude, facilities, and models that encourage scholastic achievement, and (2) familiarize the Indian child with the white culture so he is able to develop leadership qualities, and be comfortable and successful both in his own culture and in the majority, white, middle-class culture (Bishop, 1967).

Statement of the Problem

This study examines the long-term effects of the Indian Placement Program on the enrolled students" scholastic achievement as measured by standardized tests given in the schools. It also examines intelligence test scores and changes in them during years in the Program. The following effects on achievement were also examined: sex, age and grade at initial placement, and the child's adjustment as measured by number of foster homes in which he had been placed. 
CHAPTER 2

\section{REVIEW OF THE LITERATURE}

\section{Intelligence Tests}

A question frequently brought up since the development of Intelligence tests is whether or not Indian children are innately as smart as white children. If, as was assumed in the early part of this century, Indian children genetically inherit less intelligence, then the low achievement and other weaknesses in Indian education can be blamed on the children as well as on the schools. Some of the many early studies which assumed this conclusion from their results are reviewed in the following paragraphs.

The first study of Indian intelligence was in 1914 when Rowe administered the Binet-Simons Test to 547 white and 268 Indian children. The results showed only $5.8 \%$ of the Indian children performing at or above their age level. Rowe concluded that the Indians were "unquestionably slower than whites (p. 456)," and were inferior in everything to the whites. He noted, however, that the Indians were weaker in comprehension and definition than in perception and memory. Another study (Hunter \& Sommermier, 1922) found a median IQ of 82.6 for 712 Indian students on the 0tis Group Intelligence Test, and concluded a probable racial difference in intelligence or possibly in temperament. Three other early studies (Fitzgerald \& Ludeman, 1926; Garth, Schuelke, \& Abell, 1927; 
Garth, Serafini, \& Dutton, 1925) tested over 1,900 Indians with the National Intelligence Test and obtained median IQ's ranging from 68 to 87 . The Otis Group Intelligence Test was also administered to some of the same students and they scored best on performance tasks, memory, and listening comprehension, and worst on the proverbs test. The Otis Classification Test was administered to 1,000 students (Garth, Smith, \& Abell, 1928) and a median IQ of 70.4 achieved. Goodenough (1926) tested 16 racial groups on her nonlanguage human figure drawing test and found an $I Q$ of 85.6 for a select group of Indians. Only southern Negroes ranked lower. In the late 1920's thoughts on the intelligence of Indlans started to change and examiners began to feel that particular qualities of the tests themselves handicapped the Indians. These children were raised in a separate minority culture, then expected to perform well on tests prepared for and standardized only for whites and the white majority culture.

Crump (1932) in administering the Binet, Pinter-Patterson, and Goodenough individual intelligence tests found means of 90 to 93, an average of 20 points higher than the group test scores indicated for the same children, thus seriously questioning the validity of group intelligence tests for Indians. Noting that in previous studies Indian children had tended to score better on performance tasks than on verbal tasks, and realizing that many Indians are handicapped by verbal tests in English which is not their first language, Garth and Smith (1937) administered both the Pinter non-language mental test and the Otis Classification Test to 
808 subjects. This study found mental ages 1.2 to 2.5 years higher on the non-language test than the verbal test. The PInter scores were st1ll lower for the Indian children than the whites, but were 10 to 14 points higher than the Indian's scores on the Ot1s. Grade for grade and age for age, Indian performance on the Pinter was more nearly equal to white performance than was performance on the verbal test. The study also noted a good correlation $(+.57)$ between achievement and verbal intelligence, indicating that problems in school might also stem from cultural factors.

Other studies since then have supported the thesis that performance tests are more fair to Indian children and reflect more accurately their true ability than the verbal tests. Arthur (1941) using a revised form of her performance tests found a median IQ of 126 compared to a Stanford-Binet median of 94 . The performance test scores correlated better with teacher estimates of ability than the Binet and were particularly useful at the high school level. Arthur also noted that the elementary level children were at less of a disadvantage on the Binet than the older children. The reason for this may be that the earlier age level subtests of the Binet contain many more performance tasks, and as the age level progresses the abstractness of the subtests increases.

Another study using the Arthur Performance Test (Havighurst \& Hilkevitch, 1944) also found certain Indian groups to score above the average for the children on which the test was standardized. Amount of acculturation had an influence on performance on this test, with the most acculturated scoring nearest the white norms. IQ scores 
on this test did not increase with age and amount of education. A group of the children in this study was also given a verbal intelligence test, the Kuhlman-Anderson. Their mean on the Arthur was 102.8 and on the Kuhlman was 82.5. The Goodenough Draw-A-Man Test (DAM), a totally non-verbal test, was administered (Havighurst, Gunther, \& Pratt, 1946) to 325 Indian children, and again they exceeded the norms for white children by a statistically significant amount in seven of nine groups. However, the authors of this study point out the uncertainty that the DAM is a valid test of general Intelligence for Indian children because of low correlations with other tests. This is a somewhat questionable argument since the low correlation is to tests which are of doubtful validity as true measures of intelligence for Indians.

A more recent study (Howell, Evans, \& Downing, 1958) compared 100 Navajo 16 and 17 year olds to white norms for the Wechler Adult Intelligence Scale (WAIS). The Navajos were a carefully selected sample, stratified as much as possible to match the sample on which WAIS norms are based. Results again showed a verbal IQ of 84.01 , lower than the performance $I Q$ of 95.35 . The Indians performed slightly, but not significantly, better than the norm groups on two performance subtests, block design and object assembly. The authors of this study make the important comment that the "trend toward comparable conditions in the home, school and other 'American' environments may eventually decrease cultural differences and hence the need for different measures of intelligence (p. 358)." 
Cundick (1970) compared Indian children from prekindergarten to second grade on the Wechsler Pre-School and Primary Scale of Intelligence (WPPSI), the Wechsler Intelligence Scale for Children (WISC), the Peabody Picture Vocabulary Test (PPVT), and the DAM. Results showed performance on the WPPSI significantly below the norm mean on all verbal tasks and on three of five performance tasks. WISC verbal tasks were also all significantly below the mean. DAM means also were below the age mean significantly; however, by third grade the grade means on two of three drawings were at approximately the expected grade level. PPVT means were all significantly low on all grade levels. The means increased from prekindergarten to second grade but then began to drop off. This study again demonstrates the importance of exercising caution in evaluating actual inteligence of Indian children from white standardized intelligence tests, particularly verbal tests.

Acculturation. Since the $1940^{\prime}$ 's all accepted studies and experimenters have felt and sought to demonstrate that Indians score lower on intelligence tests not because of less innate ability, but because the tests are not culturally fair. Indians grow up in a different cultural environment and have less familiarity with the English language, but the intelligence tests most commonly used in schools and society are based heavily on the white American culture and the English language. Several studies have mentioned (particularly Havighurst et al., 1944; and Howell et al., 1958) that as the environment and culture of the Indian students approaches the 
white majority culture the tests more accurately reflect the student's true ability.

Studies comparing test performance with amount of Indian "blood" or genetic background have further supported the above hypothesis. Again, at first the results of these studies were used to "prove" Indian inferiority. A 1922 study (Hunter et al.) compared one-fourth, one-half, three-fourth, and full-blooded Indians and found a significant inverse relation between degree of Indian blood and score on the Otis Group Intelligence Test. Garth et al. in 1927 studied young people with one-sixteenth to seveneighths Indian heritage and found correlations with degree of Indian blood to IQ on the National Intelligence Test. Correlations varied according to grade in school, peaking at fifth grade with a +.76 correlation. The sharp decline in correlations in the succeeding grades prevented a definite conclusion, but the authors did note a trend for white blood to improve intelligenct scores. At first glance these studies seem to indicate a racial or genetic difference in intelligence, but as Bryde (1966) points out, the performance differences are better explained by cultural differences. Fullblooded Indian children tend to be more culturally isolated than mixed children and thus should be expected to score lower. Also, most of the Indian students who live in cities and are thus more exposed to the dominant culture are mixed-blooded while most of the reservation dwelling Indian students are full-blooded. Again, long-term exposure to life with a white family and culture should produce improved performances on intelligence tests for Indians, and 
scores for full-blooded Indians should approach mixed blooded Indian or white performance.

\section{Achievement Tests}

Not only on intelligence tests have Indian students traditionally performed poorly. Also on achievement tests and actual achievement performance in the schools Indians have rated low and had many signs of failure.

Kelly (1967) found that the majority of the almost 6,000 Indian students he studied were behind grade in school as measured by age. He found $43 \%$ of the students behind one year, almost $13 \%$ behind two years, $3 \%$ behind three or more years, and only $40 \%$ at expected grade level. By age 16 to $18,86 \%$ of the pupils were behind one or more years in grade level, and $44 \%$ were behind two or more years. Kelly mentioned several reasons for this, including that mothers kept about one third of the children home until they were seven years old; many students spent four years in the first three grades; and almost twice as many Indian students were retained in grade as average public school students. One third to one fourth of the Indian students' parents were involved in seasonal and temporary jobs so there was much movement to different schools. Attendance record at school was not a factor, and, in fact, the Indian attendance record was better than the non-Indian record. The dropout rate was also quite high with $22.3 \%$ of the 16 to 18 year old boys dropping out and $24.5 \%$ of the girls dropping out. Apparently, however, once the Indian students reached high school level they could graduate with little difficulty if they remained in school. 
About half of the students in this study attended non-Indian public schools and the others were enrolled in Catholic mission, federal day, federal boarding, protestant mission, and Catholic parochial schools.

Another study on Indian dropouts (Owens \& Bass, 1969) in six states found a total dropout rate of $38.7 \%$ from grades eight through twelve. The rates were almost the same for males and females. The highest percentage, 11.7, dropped out in eighth grade. Dropout rates varied greatly with tribe, for example $14.9 \%$ of the Hopi dropped out, $28.6 \%$ of the Navajo, $48.8 \%$ of the Pima, and $58.7 \%$ of the Apache students left school early. The students in this study were enrolled in public, private, and Bureau of Indian Affairs (federal) schools. No major differences were found in dropout rates between the different types of schools.

To compare Indian and white student achievement in public and boarding schools Hansen (1937) studied over 1,500 children on the Tracy Short Answer Test, an achievement test. All the Indians scored lower than the whites, although the Indian students were older. The white children excelled in every subject tested except writing. There were no clear differences between public and boarding school students.

A more recent study by Zintz (1960) compared Indians, Spanish Americans, and Anglos on several achievement tests. On the Iowa Test of Basic Skills the Indians scored consistently below national medians. They were 0.7 years low in third grade, 0.9 years in fourth grade, 1.4 years in fifth grade, and 1.5 years in the sixth grade. On 
the Gilmore Oral Reading Test the Indian students followed the same patterns and were increasingly behind norms at each grade level, from 1.6 years in comprehension and 2.7 years in accuracy behind at grade three to 3.2 years in comprehension and 2.7 years in accuracy behind at sixth grade. The Indian children also had low percentile ranks on the New Standard Vocabulary Test and the Diagnostic Reading Test. The mean for seventh to twelfth grade Indians on the Diagnostic Test for Students of English as a Second Language was 108.6 and scores of 100-125 on this test indicate that the students need a great deal of extra help in English. Apparently traditional teaching methods and schools are failing to reach the Indian students.

Two studies since the Zintz report have gone into greater depth in the specific area of reading achlevement. One (Townsend, 1961) found that about $73 \%$ of the eleventh grade and $65 \%$ of the twelfth grade Indian students scored below the twentieth percentile on national norms for the Diagnostic Reading Tests. Ninety-eight per cent of the students needed remedial reading help. The second study (Martin, 1962) researched reading achievement in Navajos in one school district. The results found the children to be at or above expected level in the first two grades, then gradually dropping down until at seventh grade every child ranked below expected grade level norms. This downward trend shifted at the end of seventh grade to a gradual improvement so that by ninth grade $8 \%$ of the students were again at or above grade level--better, but still very low reading achievement. The author does not comment on this possibility, but the reason for this shift may not be an actual improvement in 
achievement, but rather that the poorer achieving students drop out of school during these years. In this study the first seven grades had an average of 109 students tested in each grade, whereas there were only an average of 45 students tested in each grade from eighth to twelfth grade.

Probably the two most comprehensive studies of achievement have been conducted by the United States Bureau of Indian Affairs (Coombs, Kron, Collister, \& Anderson, 1958; and Peterson, 1948). The earlier study showed the progress that the schools had made in Indian education during the twenty previous years; however, still only $38 \%$ of the students were enrolled in classes at or above their expected grade level for age. Performance in comparison to standardized norms peaked at fourth grade in all achievement areas. Indian children attending public schools with white children performed better than Indian students in other types of schools, perhaps because of different populations and not necessarily because of differences in the schools. Achievement test performance was also found to be influenced by language spoken in the home, home stability, cultural background, and education of parents. The later Coombs study gathered information on over 23,000 Indian and white students. The complete battery of California Achievement Tests was administered to all the pupils. The results again showed low Indian achievement. The hierarchy of achievement was: (1) white pupils in public schools, (2) Indian public school students, (3) federal school Indians, and (4) Indian students at mission schools. The Indian students performed best on spelling and 
arithmetic fundamentals, items primarily learned by rote in school. They performed worst on reading vocabulary and arithmetic reasoning, items which are learned at home and in the community as well as at school. By the time the Indian students were in high school, they were almost five years behind white students in reading scores. Again the peak achievement was at grades four and five, and as early as fourth grade relationships between achievement and educational aspiration began to appear in the children. Significant differences in achievement were found for students from different geographic areas of the United States. Also, Indian students living off the reservation achieved better than those on the reservation, and those in town performed better than the rural students, perhaps because of cultural, language, and environmental differences. Possibly for these same reasons, it was also discovered that the less Indian "blood" a child had, and the greater amount of English he spoke prior to school entrance, the higher the child achieved. There was a slight, but inconclusive, trend for Indian students to achieve better in public schools when the majority of students in the school were white.

Early peak. Several of the previously cited studies have mentioned an early peak in performance, with Indian students falling further and further behind in each successive grade. This phenomenon has been labeled the "crossover" effect. Cowen (1943) in another achievement study found, for elementary grade level groups, that the median mental ages (MA) were above grade norms, and the median achievement scores above the MA levels. He noted a progressive 
decline in superiority of MA and achievement scores with advancing school grades. Most of the above cited studies have also found a peak in the elementary grades, usually about third or fourth grade. Another investigator (Bryde, 1966) found a peak achievement at seventh grade. He hypothesized that in the pre-teen and early teen years the alienation and identity crises are heightened in the Indian students who are torn between the cultures of their homes and their schools, and that this added conflict seriously interfers with success, motivation, and achievement. Other investigators, as reviewed in Berry (1968) have theorized that the crossover is typical of all adolescents; that elementary teachers are better skilled; that crossover is a natural result of the acculturation process; that it is a result of a change from speaking vocabulary to recognition vocabulary in school texts and expectations; or that crossover is due to a change of emphasis in schools from practical, real-iffe related subjects and curriculum in the early grades to a more abstract curriculum and subject matter which the students do not see as related to their own day to day lives in the upper grades. The actual reasons behind the crossover phenomenon are unclear, but it is undeniably a fact of life in current Indian education methods.

History of Indian Education

The ideas of Indian educational goals and types of schools have changed over the years. According to Roessel (no date) the first Indian school was established in Havana in 1568 in order to civilize and Christianize the "heathen." This was the beginning of the mission schools. These schools, still a major source of 
education for many Indians today, were the primary source of formal education for the Indians for 300 years. The philosophles of education have varied with the religious sect involved, but missionary work and Christianization have generally been important goals of these institutions (Berry, 1968).

From about 1800 until after the Civil War several of the Indian nations, notably the Choctaws and Cherokees, ran their own formal school systems. These Indians were more literate in their own languages than the average frontier white citizens were in English at that time (Indian education, 1970). These schools closed when the federal government took away their authority and forced the Indians onto reservations, and began to set up federal boarding schools. These schools were often part of treaties with individual tribes, and they sought to teach the children by taking them away from the languages and hablts of their "untutored and savage" parents. This philosophy continued with the federal schools until the Meriam report in 1928 which first publicized the scandalously low achievement record of Indian students. In criticizing the boarding schools and their philosophy, and encouraging better teachers, day schools, and cultural pride, the report influenced changes toward more public school enrollment. Later reports encouraged equating the remaining boarding schools to public schools for quality of education. For quite a few years now, public schools have been encouraged by tax benefits to enroll Indian students. Indian families have historically (Roessel, no date) had little understanding of education except that it takes the children away. 
They have found schools, particularly boarding schools, very upsetting and disruptive to the security of their extended family life pattern.

\section{LDS Placement Program}

The Indian Placement Program of the Church of Jesus Christ of Latter-day Saints (LDS Church) was established primarily as an effort to improve the Indian students' chances at education. It began unofficially in 1947 with three students, children of migrant farm workers in Richfield, Utah who, recognizing the importance of education, pleaded for an opportunity for their children to stay in Richfield during the winter and attend school (Bishop, 1967). The Program grew from three students in Richfield in 1947 to almost 5,000 students in several states currently. It began to come under church control in 1948, first as part of the Relief Society, then as a separate agency of the IDS Church, presided over by a committee of General Authorities.

In the Program, Indian children spend summers at home on the reservations with their natural families, and nine-month school years with white foster families. The natural parents must apply for their children to enter the Program, and then less than $40 \%$ of the applicants are accepted each year. Applicants must be baptized members of the church, in good health, and over eight years old. Selection is based primarily on the child's capability to take advantage of the educational opportunities of the Program and contribute to his family and community. The childrens' previous educational achievements must qualify them to compete in a nonIndian public school setting, and they can be no more than two years 
behind grade expectancy for their age. Education of the children is left almost entirely to the public schools where the children live with their foster families. Foster families are carefully screened and selected for the Program and generally have children of their own about the same age as their foster child. Ideally, the foster children are treated as simply another member of the family. To make certain the child and foster parents are adjusting well, a social worker visits the family at least once a month. The Program would appear at first to have some of the disadvantages of boarding schools, particularly taking the children out of the home. However, It does not have one of the primary boarding school disadvantages, a sterile, Institutional, non-homelike atmosphere. Indian parents appear to like the Program because frequently brothers, sisters, and other relatives of the first child to go also apply.

There has been little research on the Placement Program. Bishop (1967) reported the dropout rate to be less than 5\%, which is raised to $12-18 \%$ by the number of students leaving the Program during the summer. About $80 \%$ of the high school graduates from the Program continue school with some type of further education. These rates are noticeably better than reported in most studies of Indian achievement. However, it must be remembered that the students are specially selected for the Program by their ability to succeed in school.

One study (Bishop, 1960) on the achievement of elementary level Program children found that in school subjects the students performed best in art, music, recreation, and physical education. 
Social studies and language arts were their hardest subjects. The students achieved slightly better than their white classmates with $35 \%$ in the top third of their classes, $36 \%$ in the middle one-third, and $29 \%$ in the lower third. Most of the students required extra help from the teachers. There were some minor sex differences in achievement, but overall progress during the year was about equal for both sexes. There were some tribal differences in areas of best achievement, with the Navajo and Apache children achieving better in physical performance and use of figures, and other tribal groups achieving better in language related areas.

Purposes of this Study

The study encompassed in this thesis extends and updates the Bishop study, and more completely examines the Program's effects on scholastic achievement.

If the Program is actually reaching its goals, the Indian students should show improved achievement in school when compared to Indians who remained on the reservation. Also, as they progress through the Program each year and become more accustomed to, and thus able to succeed in, the white culture, their achievement levels should approach white norms. Each successive year in the Program should produce higher achievement, or, at least, less decline in achievement than previous studies have noted for reservation students. The usual achlevement peak and drop off in the early grades should not occur, or should, at minimum, be smaller and more gradual than the studies of reservation Indians have indicated. 
As the students have more experience with the white culture they should be less handicapped on intelligence tests, particularly verbal intelligence tests. Each successive year in the Program should be expected to produce somewhat higher intelligence scores, again particularly in verbal areas. 
CHAPTER 3

METHOD

\section{Subjects}

The names and schools of currently enrolled Placement Program students in the Wasatch Front area of Utah were obtained from the LDS Social Service offices in Salt Lake City and Orem, Utah. All students who had completed five or more continuous years in the Program as of June, 1972 were listed. This initial list included 173 names. Twenty-eight of these children, mostly from central and southern Utah, were immediately eliminated from the study because of the impracticality of traveling great distances to collect data. Of the remaining 145 students, 61 were eventually eliminated due to lack of any test information in their school records. This left 84 subjects in the study.

A more detailed breakdown of the 84 subjects follows. The male-female percentage was somewhat unequal, with 46 girls and 38 boys. Most subjects, 63, were Navajo, but other tribes were represented in the following manner: eight Hopi, three Apache, two Hualupai, two Pima, one Zuni, and five mixed. During the study Alpine School District enrolled 24 of the students; Provo had 14; Granite, 13; Jordan, 11; Nebo, 7; Salt Lake City, 5; Davis, 4; Murray, 3; and Tooele, 3. Only three of the subjects had entered the Program in 1961, and three in 1962, six in 1963, 15 in 1964, 15 in 
1965, again 15 in 1966, and 27 in 1967. During their years in the Program, 45 had lived in only one foster home, 19 in two foster homes, six in three homes, and seven in four homes. It was not possible to determine the number of homes for seven subjects. All subjects were, by Program requirements, members of the LDS Church. Most Iived in areas of the Southwest, predominantly Arizona and New Mexico, prior to their placement with the program.

\section{Measures}

Intelligence and scholastic achievement were the two main areas of interest in this study. More specifically, the six measurements used were verbal, performance (or nonverbal), and total IQ, and reading, mathematical, and language achievement, as recorded by standardized test performance. All three areas of intelligence were evaluated because, as was pointed out in the review of literature, Indians seem to be more handicapped by verbal than by nonverbal intelligence tests, and it was felt that each area of intelligence might be differently affected by the Program. These three achievement areas were selected as probably the most representative of general school work, and the most related to school success.

No tests were administered by the experimenter, but data from all standardized intelligence or achievement tests given by the schools to the subjects during their years in the Program was collected. Complete intelligence and achievement test data for every subject for every year in the Program were not available, but all available data were collected and recorded. 
Intelligence test results were recorded by intelligence quotient (IQ) scores. Achievement test results were recorded according to grade equivalent deviation scores. In order to establish expected grade equivalent scores, the school year was divided into tenths in the following manner: June 15 to September 14 was labeled .0 ; September 15 to October 14 was .1; October 15 to November 14 was .2; November 15 to December 14, .3; December 15 to January 14, .4; January 15 to February 14, .5; February 15 to March 14, .6; March 15 to April 14, .7; April 15 to May 14,.8; May 15 to June 14, .9. Thus, for example, a third grade child tested on March tenth should be expected to achieve a grade equivalent score of 3.6 . The child's actual grade equivalent score, as given in his test result norms, then provides the basis for computing a deviation score. If the child in the above example obtained a reading grade equivalent score of 2.4, a math score of 4.1, and a language score of 3.6 , his deviation scores would be $-1.2,+0.5$, and 0.0 respectively.

Different achievement and intelligence tests were administered by different school districts. For intelligence, data from the following tests were collected: 73 California Tests of Mental Maturity, 18 Lorge Thorndike, nine Otis-Lennon, five Pinter, and one Wechsler Intelligence Scale for Children (WISC). AIl of these tests, except the WISC and Pinter, are standardized to a mean of 100 and a standard deviation of 16 , and therefore scores on each test can be legitimately compared. The WISC and Pinter means are 100, but their standard deviations are 15. This difference was compensated for so that these scores can be examined together with scores from the other 
tests. Complete verbal, performance, and total IQ scores were not available for every test administration.

Six different achievement tests were administered in the various districts. The total number of tests recorded included: 81 Stanford Achievement Tests, 47 Iowa Tests of Basic Skills, 28 California Achievement Tests, nine Metropolitan Achievement Tests, five Comprehensive Tests of Basic Skills, and three SRA Achievement Series Tests. The use of grade equivalent deviation scores allows scores from the different tests to be equated and compared.

In addition, to closer evaluate the subjects' intelligence and achievement, and the specific factors affecting each, several other areas, defined below, were examined.

It was postulated, because of changes in society, the school systems, the Placement Program, and perhaps in the acceptance of the Indian children, that the year the child was originally placed might affect his performance. Year of placement in this study ranged from 1961 to 1967.

Beginning grade, the subject's grade in school when initially placed, could also be an important factor in his scores. The amount of previous experience in other types of schools and settings might reasonably influence motivation, goals, and self concept, all important elements in effort and thus in performance. Beginning grades ranged from first to eighth.

The subject's age at initial placement in the Program, labeled "beginning age," would largely determine the quantity of exposure to Indian culture. Also, perhaps, the myriad of adjustments 
required by placement in a foster home would be easier at a certain age. Both possibilities could reasonably influence achievement on standardized tests.

The number of foster homes the child had been placed in during his enrollment in the Program is perhaps a signal of his social and familial adjustment. The number of homes in which subjects had lived ranged from one home during 11 years in the Program, to four homes in five years. A large number of homes would probably prove disruptive, and might both contribute to and be an indication of emotional or social conflicts and problems. These problems could likely influence school and test performance.

The last factor reviewed, pertaining only to achievement test data, was the particular achievement test which the chlld was given. In a visual review of the data it appeared that subjects' scores were reasonably equivalent on all achievement tests except the Stanford Achievement Test. For some reason, this test appeared to place the Indians at a greater disadvantage. The Stanford Test was the most frequently given achievement test in this geographic area, according to the data collected in this study.

\section{Procedures}

After gathering the list of the names and schools of subjects, permission was obtained from the school districts to review each subject's cumulative file and to collect all data available from standardized tests. Each school where subjects were enrolled was visited by the experimenter, and the data gathered. 
The data were recorded and organized according to the number of years the subject had been in the program, regardless of his year of placement. Scores for the subjects' sixth and later years in the Program were grouped together in a $6+$ category because of small N's for these years. Year of placement, current grade level, tribal affiliation, and other identifying data were recorded for each subject.

Two school districts, Murray and Jordan, were hesitant because of the confidentiality of the test records, and would not allow the experimenter to personally examine their files. Nevertheless, they were willing to, and did, submit their data on anonymous subjects, that is, they Identified each subject by a few characteristics (sex, grade, and year placed) rather than by name.

\section{Data Treatment}

Means, according to sex, year in Program, and year of placement were computed for each of the six test score measurements. Also, a two-way analysis of variance, using sex and number of years in the Program, was computed on each of the six areas. When an analysis indicated a significant difference made by years in program, a Newman-Keuls test was performed to determine exactly which years were significantly different.

Then, further analyses of variance were computed, using three covariates for each section of intelligence (year of placement, beginaing grade, and beginning age) and four covariates for each area of achievement (year of placement, beginning grade, beginning age, and achievement test). To examine the effect of number of homes, 
Pearson correlation coefficients were computed for each of the six test areas. Correlations were made using only test scores for the fourth and later years in Program because the students who change homes do so normally only at the end of a complete year in one home, and therefore the effect of four homes, the maximum in this study, would not be felt until the student was in at least his fourth year of placement.

$\underline{\text { Design }}$

This study is basically a cross sectional examination of longitudinal data. Ideally, a longitudinal study could have been performed with a large sample of students, all given the same Intelligence and achievement tests at the same time annually, for several years. Since a study requiring that length of time was not possible, the current study was developed. It was initially hoped that sufficient annual test data would be available on enough students to do a longitudinal study. This was not possible, however, because of data sketchiness and incompleteness. Only a very few subjects--2--had complete achievement test data for each year, and none had complete yearly intelligence data.

Independent variables for this study are the numbers of years the subjects have been in the Placement Program, and their sex. The dependent variables are the test scores. It is a two way design. 
CHAPTER 4

RESULTS

The results of this study show several areas of significant interest to both the present and future of the Indian Placement Program. Results are presented below according to each particular area of achievement or intelligence. Covariates and other factors which may have influenced the results are then reported at the end of this chapter.

Mathematical Achievement

Indian students in the Placement Program performed an average of almost one year below expected achievement in the area of math. As shown on Table 1, no group of subjects, except females in their first year in the Program, performed above expected level, and some students performed an average up to 2.12 years below expected grade level.

The subjects' math achievement scores were significantly Influenced both by the number of years the subject had been involved in the Program, and by his sex. Table 2 presents the results of an analysis of variance.

The direction of the sex difference is obvious from the mean deviation scores presented in Table 1. The males scored significantly worse in math than the females. 
TABLE 1

Math Achievement Mean Deviation Scores as a

Function of Sex and Year in Program

\begin{tabular}{cccccccc}
\hline \hline Sex & \multicolumn{7}{c}{ Year } \\
& 1 & 2 & 3 & 4 & 5 & $6+$ & Total \\
\hline Male & -0.52 & -0.80 & -0.91 & -1.38 & -1.39 & -2.12 & -1.19 \\
Female & +0.05 & -0.49 & -1.08 & -1.04 & -0.75 & -1.25 & -0.76 \\
Total & -0.24 & -0.65 & -0.99 & -1.21 & -1.07 & -1.68 & -0.98 \\
N & 24 & 36 & 32 & 29 & 29 & 17 & 167 \\
\hline
\end{tabular}

TABLE 2

Effects of Sex and Years in Program on Math Achievement

\begin{tabular}{lcccc}
\hline \multicolumn{1}{c}{ Source } & df & MS & F & p \\
\hline Sex (A) & 1 & 6.850 & 5.074 & $<.05$ \\
Years in Program (B) & 5 & 5.211 & 3.860 & $<.01$ \\
A X B & 5 & 0.797 & 0.590 & n.s. \\
Error & 158 & 1.349 & & \\
\hline
\end{tabular}

A Newman-Keuls test was performed on the years in Program mean scores, and is presented in Table 3 . A pooled $N$ was used in figuring this test because the type of data and data collection encouraged a different $\mathbf{N}$ for each cell. The test indicated significant differences at the .05 level only for the first with third, fourth, fifth, and 
sixth plus years, and second with sixth plus year scores. After the third year in the Program scores were not significantly affected by further years of involvement. In each case where significant differences were found, as can be seen on Table 1, the subjects scored better in their first or second year in the Program than in their later years.

TABLE 3

Test on Math Achievement Mean Scores for Years in Program

(Newman-Keuls)

\begin{tabular}{|c|c|c|c|c|c|c|}
\hline Year & 1 & 2 & 3 & 5 & 4 & $6+$ \\
\hline Ordered Means & 0.24 & 0.65 & 0.99 & 1.07 & 1.21 & 1.68 \\
\hline 0.24 & $-\infty$ & 0.41 & $0.75^{*}$ & $0.83^{*}$ & $0.97^{*}$ & $1.44 *$ \\
\hline 0.65 & & $-\infty$ & 0.34 & 0.42 & 0.56 & $1.03^{*}$ \\
\hline 0.99 & & & - & 0.08 & 0.22 & 0.69 \\
\hline 1.07 & & & & -. & 0.14 & 0.61 \\
\hline 1.21 & & & & & - & 0.47 \\
\hline 1.68 & & & & & & - \\
\hline \multicolumn{7}{|l|}{ Truncated } \\
\hline Range & & 2 & 3 & 4 & 5 & 6 \\
\hline$q(r, 157)$ & & 2.80 & $3 \cdot 36$ & 3.69 & 3.92 & 4.10 \\
\hline$q \sqrt{\text { mserr/28 }}$ & & 0.62 & 0.74 & 0.81 & 0.86 & 0.90 \\
\hline
\end{tabular}


Reading Achievement

Subjects performed an average of almost one year below grade expectation in reading achievement. No group of subjects functioned at or above expected level, and the greatest mean deviation was -1.68. The mean deviations are presented in Table 4.

TABLE 4

Reading Achievement Mean Deviation Scores as a Function of Sex and Year in Program

\begin{tabular}{cccccccc}
\hline \hline Sex & 1 & 2 & 3 & 4 & 5 & $6+$ & Total \\
\hline Male & -0.42 & -0.95 & -0.82 & -0.90 & -1.45 & -1.68 & -1.04 \\
Female & -0.15 & -0.59 & -1.22 & -1.31 & -1.07 & -0.41 & -0.79 \\
Total & -0.29 & -0.77 & -1.02 & -1.10 & -1.26 & -1.05 & -0.92 \\
N & 22 & 38 & 32 & 29 & 29 & 17 & 167 \\
\hline
\end{tabular}

Although the trend for males to do worse than females, and for both sexes to do worse each consecutive year in the program is apparent in Table 4, an analysis of variance, as presented in Table 5, indicated that sex and year in Program made no significant difference in reading achievement.

Ianguage Achievement

The subjects were almost one year behind in language achievement. Mean scores for groups ranged from +.04 for females in their first year to -2.15 for males in their sixth plus years. Results are presented in Table 6. 
TABLE 5

Effects of Sex and Years in Program on Reading Achievement

\begin{tabular}{lcccc}
\hline Source & df & MS & F & p \\
\hline Sex (A) & 1 & 2.354 & 1.528 & n.s. \\
Years in Program (B) & 5 & 2.965 & 1.925 & n.s. \\
A X B & 5 & 2.099 & 1.362 & n.s. \\
Error & 158 & 1.540 & & \\
\hline
\end{tabular}

TABLE 6

Language Achievement Mean Deviation Scores as a Function of Sex and Year in Program

\begin{tabular}{|c|c|c|c|c|c|c|c|}
\hline \multirow{2}{*}{ Sex } & \multicolumn{7}{|c|}{ Year } \\
\hline & 1 & 2 & 3 & 4 & 5 & $6+$ & Total \\
\hline Male & -0.58 & -1.02 & -1.07 & -1.02 & -1.35 & -2.15 & -1.20 \\
\hline Female & +0.04 & -0.22 & -0.91 & -0.92 & -1.23 & -0.97 & -0.70 \\
\hline Total & -0.27 & -0.62 & -0.99 & -0.97 & -1.29 & -1.56 & -0.95 \\
\hline $\mathbf{N}$ & 22 & 38 & 32 & 30 & 28 & 17 & 167 \\
\hline
\end{tabular}

As shown in Table 7, sex made a significant difference in language achievement with females performing better than males. Number of years of involvement in the Program did not affect a significant difference in language achievement. However, the trend 
was again for greater negative deviation from expected level with each successive year in the Program.

TABLE 7

Effects of Sex and Years in Program on Language Achievement

\begin{tabular}{lcccc}
\hline \multicolumn{1}{c}{ Source } & df & MS & F & p \\
\hline Sex (A) & 1 & 9.344 & 4.088 & $<.05$ \\
Years in Program (B) & 5 & 4.681 & 2.048 & n.s. \\
A X B & 5 & 1.113 & 0.531 & n.s. \\
Error & 158 & 2.229 & & \\
\hline
\end{tabular}

\section{Verbal Intelligence}

Data for the three areas of intelligence, and particularly for verbal and performance intelligence were more sketchy and incomplete than achievement test data. Also, the N's were smaller. These facts should be considered when reviewing the intelligence test results; however, all available intelligence data for this population were obtained and are considered in the analyses.

Verbal intelligence scores for the subjects averaged 86.7 , within the dull-normal range. IQ scores for the different groups ranged from 72.5 for females in their sixth plus years to 96.5 for females in their second year. The complete mean scores are presented in Table 8. 
TABLE 8

Verbal IQ Mean Scores as a Function

of Sex and Year in Program

\begin{tabular}{cccccccc}
\hline \hline Sex & & \multicolumn{7}{c}{ Year } \\
& 1 & 2 & 3 & 4 & 5 & $6+$ & Total \\
\hline Male & 87.6 & 90.0 & 79.1 & 90.0 & 83.0 & 87.3 & 86.2 \\
Female & 91.7 & 96.5 & 85.8 & 89.4 & 87.0 & 72.5 & 87.2 \\
Total & 86.7 & 93.3 & 82.5 & 89.7 & 85.0 & 79.8 & 86.7 \\
N & 8 & 17 & 13 & 16 & 14 & 6 & 74 \\
\hline
\end{tabular}

Table 9 indicates that sex was not a significant factor influencing verbal IQ scores. Number of years in Program was, however, significant to the .05 level.

TABLE 9

Effects of Sex and Years in Program on Verbal IQ

\begin{tabular}{lcccc}
\hline \multicolumn{1}{c}{ Source } & df & MS & F & p \\
\hline Sex (A) & 1 & 0.813 & 0.523 & n.s. \\
Years in Program (B) & 5 & 4.279 & 2.754 & $<.05$ \\
A X B & 5 & 1.692 & 1.089 & n.s. \\
Error & 97 & 1.554 & & \\
\hline
\end{tabular}

A Newman-Keuls test on the specific significant scores for years in Program is presented in Table 10. A pooled $\mathbf{N}$ was used in the 
test. The test indicates significant differences at the .05 level for scores for first with second, third, and sixth plus years, second with third, fourth, fifth, and sixth plus years, third with fourth, fourth with fifth, and sixth plus, and fifth with sixth plus years. These results are difficult to interpret because the mean scores for successive years did not follow a linear trend. As presented in Figure 1, the highest scores were received the second year in the Program, but the lowest scores were in the third year. Scores rose again the fourth year, then settled into a downward trend the remaining years. Small N's, particularly for the first and sixth plus years, may have contributed to the variation, and thus any conclusions about trend or pattern of verbal intelligence during years of placement must be tentative.

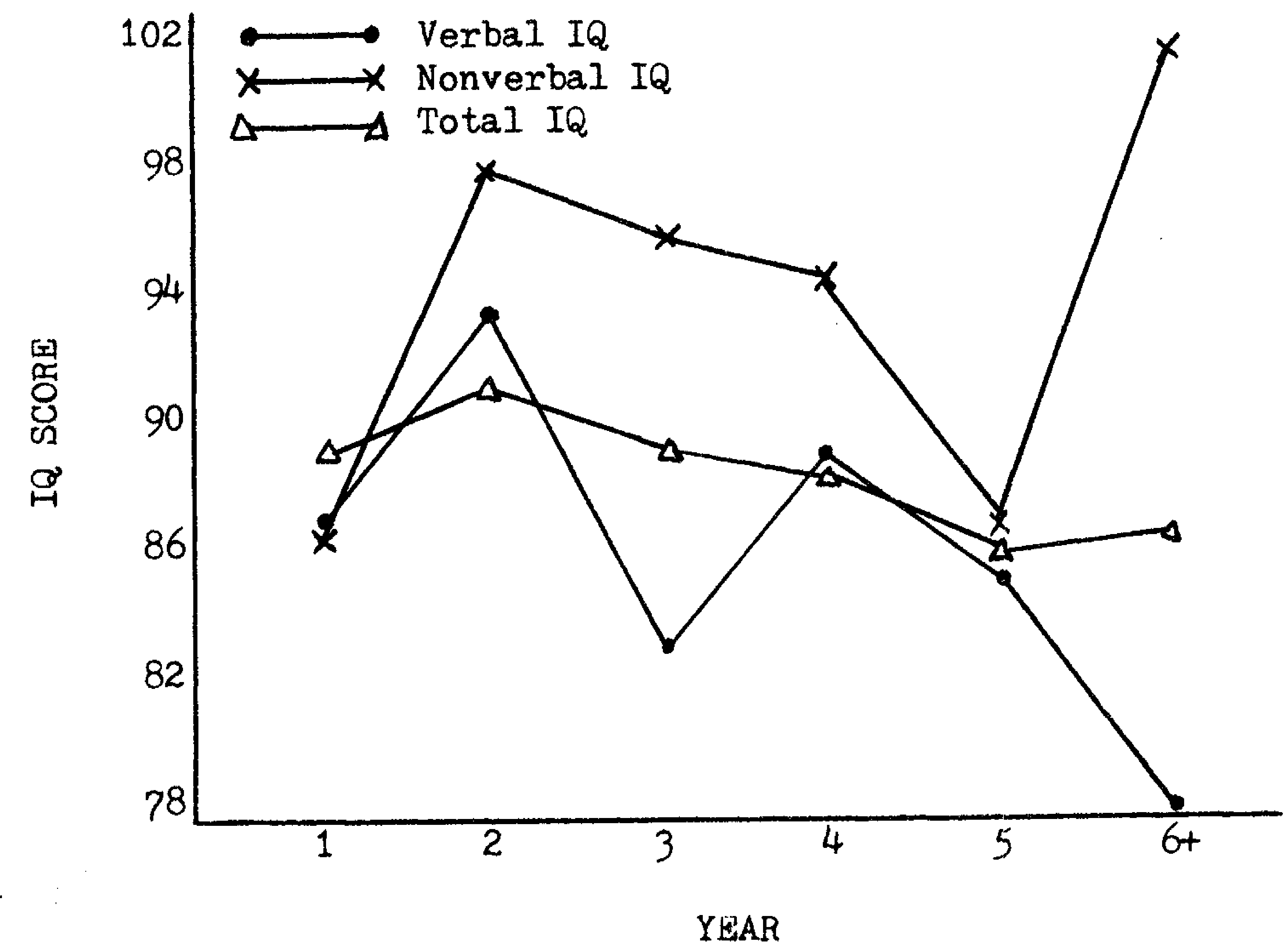

Fig. 1. Mean IQ scores by year in Program 
TABLE 10

Test on Verbal Intelligence Mean Scores

for Years in Program

(Newman-Keuls)

\begin{tabular}{|c|c|c|c|c|c|c|}
\hline Year & $6+$ & 3 & 5 & 1 & 4 & 2 \\
\hline Ordered Means & 79.8 & 82.5 & 85.0 & 86.7 & 89.7 & 93.3 \\
\hline 71.8 & -- & 2.7 & $5.2^{*}$ & $6.9^{*}$ & $9.9^{*}$ & $13.5^{*}$ \\
\hline 82.5 & & - & 2.5 & $4.2^{*}$ & $7.2^{*}$ & $10.8 *$ \\
\hline 85.0 & & & -- & 1.7 & $4.7^{*}$ & $8.3^{*}$ \\
\hline 86.7 & & & & -- & 3.0 & $6.6 *$ \\
\hline 89.7 & & & & & -- & $3.6 *$ \\
\hline 93.3 & & & & & & - \\
\hline \multicolumn{7}{|l|}{ Truncated } \\
\hline Range & & 2 & 3 & 4 & 5 & 6 \\
\hline$q(r, 97)$ & & 2.82 & $3 \cdot 38$ & $3 \cdot 72$ & 3.95 & 4.13 \\
\hline$q \sqrt{\text { mserr } / 13}$ & & 3.07 & 3.68 & 4.05 & 4.31 & 4.50 \\
\hline
\end{tabular}

Nonverbal Intelligence

Performance, or nonverbal, intelligence scores averaged

93.7. This is within the average range and is about seven points higher than the verbal IQ score average. As shown in Table 11, mean scores ranged from a low of 76.7 for first year females to a high of 102.7 for sixth plus year males. 
TABLE 11

Nonverbal IQ Mean Scores as a Function

of Sex and Year in Program

\begin{tabular}{cccccccc}
\hline \hline Sex & & \multicolumn{7}{c}{ Year } \\
& 1 & 2 & 3 & 4 & 5 & $6+$ & Total \\
\hline Male & 96.3 & 96.3 & 98.5 & 94.1 & 77.3 & 102.7 & 94.2 \\
Female & 76.7 & 98.6 & 93.0 & 95.0 & 95.2 & 100.0 & 93.1 \\
Total & 86.5 & 97.5 & 95.8 & 94.6 & 86.3 & 101.3 & 93.7 \\
N & 8 & 17 & 13 & 16 & 14 & 6 & 74 \\
\hline
\end{tabular}

There were no significant sex differences in nonverbal intelligence, but the number of years in the Program was a highly significant factor in intelligence scores. Table 12 presents the analysis of variance.

TABLE 12

Effects of Sex and Years in Program on Nonverbal IQ

\begin{tabular}{lcccc}
\hline Source & df & MS & F & ! \\
\hline Sex (A) & 1 & 0.714 & 0.390 & n.8. \\
Years in Program (B) & 5 & 6.378 & 3.486 & $<.01$ \\
AX B & 5 & 2.359 & 1.289 & n.8. \\
Error & 97 & 1.829 & & \\
\hline
\end{tabular}


To further determine the exact influence of years in Program, a Newman-Keuls test was performed. The results of this test are presented in Table 13. A pooled $N$ was again used. Significance to the .05 level was found between the following years: first with second, third, fourth, and sixth plus, second with fifth, and sixth plus, and fifth with sixth plus. As shown in Figure 1, there were peaks at both the second and sixth plus years, and the lowest scores were at the fifth year. Again, although the trend is apparent, small N's may have contributed to the variation of scores, and thus limit the conclusions that can be drawn.

Total Intelligence

Total intelligence scores averaged 88.3 , which is within the dull-normal range of intelligence. There was a higher $\mathrm{N}$ for total IQ scores than for verbal or nonverbal IQ scores, and a smaller range between the mean scores. All scores fell between 82 and 94 . Mean results are presented in Table 14.

The pattern of scores, similar to verbal and nonverbal IQ, peaked at the second year; however, an analysis of variance indicated that there were no significant differences within years in Program. Sex differences were also not significant. Table 15 presents the analysis of variance data, and Figure $I$ shows the mean total IQ scores in graphic form.

Covarlates and Other Factors

Math Achievement. As shown on Table 15, when year of placement was held constant as a covariate there was no significant sex 
TABLE 13

Test on Nonverbal Intelligence Mean Scores for Years in Program

(Newman-Keuls)

\begin{tabular}{|c|c|c|c|c|c|c|}
\hline Year & 5 & 1 & 4 & 3 & 2 & $6+$ \\
\hline Ordered Means & 86.3 & 86.5 & 94.6 & 95.8 & 97.5 & 101.3 \\
\hline 86.3 & -- & 0.2 & $8.3^{*}$ & $9.5^{*}$ & $11.2^{*}$ & $1.5 .0 *$ \\
\hline 86.5 & & -- & $8.1^{*}$ & $9 \cdot 3^{*}$ & $11.0^{*}$ & $14.8 *$ \\
\hline 94.6 & & & -- & 1.2 & 2.9 & $6.7^{*}$ \\
\hline 95.8 & & & & -- & 1.7 & $5.5^{*}$ \\
\hline 97.5 & & & & & - & $3.8^{*}$ \\
\hline 101.3 & & & & & & -- \\
\hline \multicolumn{7}{|l|}{ Truncated } \\
\hline Range & & 2 & 3 & 4 & 5 & 6 \\
\hline$q(r, 97)$ & & 2.82 & $3 \cdot 38$ & 3.72 & 3.95 & 4.13 \\
\hline$q \sqrt{\text { mserr } / 13}$ & & $3 \cdot 36$ & 4.02 & 4.43 & 4.70 & 4.91 \\
\hline
\end{tabular}


TABLE 14

Total IQ Mean Scores as a Function of Sex and Year in Program

\begin{tabular}{llllllll}
\hline \hline Sex & \multicolumn{7}{c}{ Year } \\
& 1 & 2 & 3 & 4 & 5 & $6+$ & Total \\
\hline Male & 92.0 & 93.4 & 86.6 & 88.9 & 82.3 & 84.9 & 88.0 \\
Female & 85.6 & 89.8 & 90.0 & 88.6 & 89.8 & 87.3 & 88.6 \\
Total & 88.8 & 91.6 & 88.3 & 88.8 & 86.1 & 86.1 & 88.3 \\
N & 18 & 29 & 19 & 20 & 16 & 6 & 108 \\
\hline
\end{tabular}

TABLE 15

Effects of Sex and Years in Program on Total IQ

\begin{tabular}{lcccc}
\hline \multicolumn{1}{c}{ Source } & df & MS & F & p \\
\hline Sex (A) & 1 & 0.053 & 0.033 & n.s. \\
Years in Program (B) & 5 & 0.684 & 0.417 & n.s. \\
A X B & 5 & 0.893 & 0.544 & n.s. \\
Error & 97 & 1.634 & & \\
\hline
\end{tabular}

difference in Math achievement. This is in contrast to the straight analysis of variance of Table 2 , and indicates that much of the apparent sex difference was a result of the year of placement factor, and that math achievement did not actually differ with sex. Years in Program and interaction remained the same under this covariate as under 
a straight analysis. Mean scores for the first and second year in Program with placement from 1962 to 1967 were $+.30,+.20,+.10,-.32$, -.35 , and -.86 for each year respectively. There was a definite trend for subjects who were placed in later years to do worse in math their first two years than subjects initially placed in earlier years; however, small N's limit generalizability.

\section{TABLE 16}

Effects of Sex and Years in Program on Math Achievement with Year of Placement as a Covariate

\begin{tabular}{lcccc}
\hline \hline Source & df & MS & F & p \\
\hline Sex (A) & 1 & 3.444 & 2.703 & n.s. \\
Years in Program (B) & 5 & 6.970 & 5.470 & $<.01$ \\
A X B & 5 & 0.631 & 0.495 & n.s. \\
Error & 157 & 1.274 & & \\
\hline
\end{tabular}

When beginning grade was the covariate, as in Table 17, the year in Program significant differences remained at the same level, but sex was no longer significant. This indicates interaction between beginning grade and sex as factors influencing math achievement, and that sex alone was not a significant factor.

When the covariate was achlevement test, as in Table 18 , the slgnificance of the sex factor increased while the year in Program significance remained at the same level. This indicates that the particular achievement test administered had an unequal effect on males and females. 
TABLE 17

Effects of Sex and Years in Program on Math Achievement with Beginning Grade as a Covariate

\begin{tabular}{|c|c|c|c|c|}
\hline Source & $d f$ & MS & $F$ & $p$ \\
\hline $\operatorname{Sex}(A)$ & 1 & 4.705 & 3.581 & n.s. \\
\hline Years in Program (B) & 5 & 6.015 & 4.585 & $<.01$ \\
\hline$A \times B$ & 5 & 0.847 & 0.645 & n.s. \\
\hline Error & 157 & 1.312 & & \\
\hline
\end{tabular}

TABLE 18

Effects of Sex and Years in Program on Math Achievement with Achievement Test as a Covariate

\begin{tabular}{lcccc}
\hline \multicolumn{1}{c}{ Source } & df & MS & F & p \\
\hline Sex (A) & 1 & 8.535 & 5.195 & $<.025$ \\
Years in Program (B) & 5 & 4.332 & 3.386 & $<.01$ \\
A X B & 5 & 1.238 & 0.967 & n.s. \\
Error & 157 & 1.279 & & \\
\hline
\end{tabular}

The covariate for beginning age, with an F-rat1o of 0.817 was not significant.

When math achievement scores in the fourth, fifth, and sixth plus years were correlated to number of homes, the correlation coefficient was +.241 , which is not significant. Number of homes $d 1 d$ not significantly affect math achievement. 
Reading Achievement. As shown in Table 19, none of the covariates reached levels of significance. Reading and achievement was not affected by the factors tested.

Reading scores correlated +.115 with number of homes. This correlation is not at a significant level.

TABLE 19

Covariate Effect on Reading Achievement Scores

\begin{tabular}{lcccc}
\hline \multicolumn{1}{c}{ Covariate } & df & MS & F & p \\
\hline Year of Placement & 1 & 4.772 & 3.140 & n.s. \\
Beginning Grade & 1 & 4.692 & 3.087 & n.s. \\
Beginning Age & 1 & 1.946 & 1.265 & n.s. \\
Achievement Test & 1 & 0.492 & 0.318 & n.s. \\
\hline
\end{tabular}

Language Achievement. Year of placement as the covariate presented in Table 20 showed no significant sex difference but a year in Program difference significant to the .025 level. This is in sharp contrast to the analysis of variance of Table 7 which indicated .05 level significance for sex difference and no significant years in Program difference. The contrast between the two analyses implies that year of placement interacts with sex to give an apparent, but not real, sex difference. Year of placement also interacted with year in Program to mask a significant years in Program effect. The mean first and second year in Program language achievement scores according to year of placement were as follows: 1961, t0.90; 1962, $-0.50 ; 1963$, 
$-0.20 ; 1964,+0.30 ; 1965,-0.24 ; 1966,-0.10 ;$ and $1967,-1.00$. There is no clear trend in these scores, and small N's prevent definite conclusions.

TABLE 20

Effects of Sex and Years in Program on Language

Achievement with Year of Placement as a Covariate

\begin{tabular}{lcccc}
\hline \multicolumn{1}{c}{ Source } & df & MS & F & p \\
\hline Sex (A) & 1 & 4.705 & 2.154 & n.s. \\
Years in Program (B) & 5 & 6.873 & 3.144 & $<.025$ \\
A X B & 5 & 1.219 & 0.557 & n.8. \\
Error & 157 & 2.185 & & \\
\hline
\end{tabular}

Beginning grade was also an important covariate for language achievement, as shown on Table 2l. With this covariate, years in Program, which was not significant on Table 7 , became significant, and sex was no longer significant. Apparently sex interacted with beginning grade and other factors to produce a falsely apparent effect. The effect of years in Program was further masked by interaction with another covariate factor.

Beginning age, presented in Table 22, was another slgnificant factor in language achievement. This time the sex effect remained the same, but again another of the elements masking years in Program effect appeared. 
TABLE 21

Effects of Sex and Years in Program on Language Achievement with Beginning Grade as a Covariate

\begin{tabular}{lcccc}
\hline Source & df & MS & F & p \\
\hline Sex (A) & 1 & 7.412 & 2.452 & n.s. \\
Years in Program (B) & 5 & 6.042 & 2.739 & $<.05$ \\
A X B & 5 & 1.126 & 0.502 & n.s. \\
Error & 157 & 2.206 & & \\
\hline
\end{tabular}

TABLE 22

Effects of Sex and Years in Program on Language Achievement with Beginning Age as a

Covariate

\begin{tabular}{lcccc}
\hline \multicolumn{1}{c}{ Source } & df & MS & F & p \\
\hline Sex (A) & 1 & 10.182 & 4.546 & $<.05$ \\
Years in Program (B) & 5 & 5.866 & 2.619 & $<.05$ \\
A X B & 5 & 1.126 & 0.502 & n.s. \\
Error & 157 & 2.239 & & \\
\hline
\end{tabular}

Achievement test as a covariate had less effect. Years in Program remained nonsignificant, but sex significance increased from .05 in Table 7 to .025 in Table 23. This indicates, similar to the math achievement situation, an increased achievement score inequality between the sexes. For some reason, the language section of the Stanford Achievement test was harder for males. 
TABLE 23

Effects of Sex and Years in Program on Language

Achievement with Achievement Test as a

Covariate

\begin{tabular}{lcccc}
\hline \hline Source & df & MS & F & p \\
\hline Sex (A) & 1 & 12.259 & 5.746 & $<.025$ \\
Years in Program (B) & 5 & 3.766 & 1.765 & n.s. \\
A X B & 5 & 1.073 & 0.502 & n.s. \\
Error & 157 & 2.133 & & \\
\hline
\end{tabular}

Number of homes correlated +.230 , not significantly, with

language achievement scores.

Verbal Intelligence. None of the covariates tested had a significant effect on verbal inteligence. Table 24 presents these covariates.

TABLE 24

Covariate Effect on

Verbal IQ Scores

\begin{tabular}{lllll}
\hline \multicolumn{1}{c}{ Covariate } & df & MS & F & p \\
\hline Year of Placement & 1 & 5.560 & 0.356 & n.s. \\
Beginning Grade & $I$ & 26.794 & 1.738 & n.s. \\
Beginning Age & 1 & 12.596 & 0.809 & n.s. \\
\hline
\end{tabular}


Number of homes did not correlate significantly $(+.012)$ with verbal intelligence.

Nonverbal Intelligence. None of the covariates tested had a significant effect on nonverbal intelligence. Table 25 presents these covariates.

TABLE 25

Covariate Effect on Nonverbal

IQ Scores

\begin{tabular}{lcccc}
\hline \multicolumn{1}{c}{ Covariate } & df & MS & F & p \\
\hline Year of Placement & 1 & 20.424 & 1.118 & n.s. \\
Beginning Grade & 1 & 13.972 & 0.762 & n.s. \\
Beginning Age & 1 & 5.094 & 0.276 & n.s. \\
\hline
\end{tabular}

Number of homes did not correlate significantly $(+.031)$ with nonverbal intelligence.

Total Intelligence. None of the covariates tested had a significant effect on total intelligence. Table 26 presents these covariates.

Number of homes, however, with a coefficient of -.757 , correlated significantly to the .01 level with total intelifgence scores. The more homes in which subjects had lived, the poorer they performed. 
TABLE 26

Covariate Effect on Total

IQ Scores

\begin{tabular}{lllll}
\hline \multicolumn{1}{c}{ Covarlate } & df & MS & F & $p$ \\
\hline Year of Placement & 1 & 0.073 & 0.044 & $\cdot$ n.s. \\
Beginning Grade & 1 & 0.072 & 0.043 & n.s. \\
Beginning Age & 1 & 1.257 & 0.766 & n.s. \\
\hline
\end{tabular}


CHAPTER 5

\section{DISCUSSION}

\section{Scholastic Achievement}

Academic achievement, as measured by deviation scores on standardized achievement tests, did not show the expected yearly improvements. In fact, significant annual declines from expected achievement were found for math. In addition, reading and language achievement scores tended to decline from expected level with successive years in the Placement Program. The yearly decrease in language scores also became significant when the masking factors of beginning grade and year of placement were held constant as covariates. Subjects performed closer to expectation when they entered the Program than after they had participated in it for several years. Achlevement test results do not support the LDS Indian Placement Program goal of providing Indian children with a better education. This outlook does not improve when the Program subjects' results are compared to data from the literature on reservation Indians' scholastic achievement. Only one study (Zintz, 1960) gives a detailed breakdown of grade equivalent scores for math and language achievement. On the math section of the Iowa Test of Basic Skills (ITBS) Indian subjects received deviation scores ranging from -0.6 in third grade to -1.0 in sixth grade. Most Program students were Initially placed in third grade where their math deviation score mean 
was -0.24 . By the third year in the Program, sixth grade for most subjects, the deviation score mean was -0.99 . These results correlate closely with the Zintz results, indicating that Program student performance was not superior to performance of reservation students.

On the language section of the ITBS in the Zintz study, deviation scores ranged from -0.5 in third grade to -0.9 in sixth grade. Placement Program students performed about the same with deviation scores ranging from -0.27 the first year in the Program (third grade for most) to -0.99 the third year in the Program (sixth grade for most subjects).

Although this study had no control group of subjects who did not enroll in the Program, the literature does show a pattern of achievement typical of students who remain at home and are educated there. The expectation that Indian students in the Placement Program would show improved achievement over the Indians who remained at home was not supported, at least in math and language areas.

There is somewhat more literature that can be compared to this study in the area of reading achievement. Townsend (1963) found most of the eleventh and twelfth grade Indians he tested on the Diagnostic Reading Test and the Gates Reading Survey to be at least five years below expected grade level. The Martin study (1962) found a group of Navajo children tested on the reading section of the California Achievement Test to be 2.1 years below expectation by seventh grade, and 3.2 years behind by twelfth grade. Another study (Zintz, 1960) used three different reading achievement tests. The Indians were 1.9 years behind at grade 5.8 on the Gates Survey. On the Gilmore Oral 
Reading Test subjects' grade equivalent deviation scores ranged from -1.4 in third grade to -2.9 in sixth grade. On the reading subtest of the ITBS deviation scores ranged from -0.7 at third grade to -1.1 at sixth grade. Reading deviation scores for Placement Program students ranged from -0.29 the first year in Program (most of ten third grade), to -1.02 the third year (usually sixth grade), to -1.05 in sixth and later years (ninth and higher grades usually). Reading achievement scores for Program students seem to be better than most of the scores recorded in the literature for reservation students. It appears that Program students may have an even greater advantage in reading over their reservation peers in the upper grades. Program subjects' performance compared most favorably with studies using eleventh and twelfth grade Indian subjects, but was about the same as performances reported in studies using elementary level subjects.

Direct comparison between the various studies in reading, as well as in language and math, is not completely legitimate because of differences in the populations, score breakdowns, dates of studies and tests given. Also, further conclusions are difficult and limited without more comparable literature on achievement in upper grades.

A breakdown of achievement scores by grade levels was not made, and therefore the exact crossover effect could not be determined. The breakdown of achievement scores by years in Program, which is closely but not exactly correlated to grade level, showed no crossover, but just a gradual constant declining tendency. Perhaps 
the early peak, if present, occurs before placement or is masked by this method of handling the data.

The other factors which had significant effects on achievement results should be noted. Year of placement was a significant factor with an unexpected trend for subjects to do better if placed in 1.961 or 1962 than if placed in later years. The reason for this decline In achievement scores is unknown and can at this point only be speculated about--perhaps a decrease in ability or motivation of students enrolled in the Program, or a change in previous or placement school experiences. In any case, this trend is only that, a trend, and small N's, particularly in the earlier years, prohibit further conclusions.

Beginning age and beginning grade were significant covariate factors to consider. Both interacted with sex to create an apparent, but not real, sex difference on the analyses of math and language achievement. Also, both interacted with year in Program to mask a real years difference in math and language analyses. These factors must be considered in order to understand the true findings of this study.

Another covariate of importance was achievement test. The different performance by Indians on various intelligence tests has long been noted, while possibly achievement test differences have been ignored. School districts should be aware that Indian students may be at a greater disadvantage on the Stanford Achievement test and that males in particular may be handicapped. 
It was anticipated that greater number of homes might adversely affect achlevement. This factor had no effect on achievement.

Intelligence

Successive years in the Placement Program did not produce the anticipated improvement in verbal intelligence scores. Scores, in fact, declined during consecutive years after a peak the second year and a smaller peak the fourth year. This is a difficult pattern to interpret, and explanations at this point would be mere conjecture. Although verbal IQ scores for Program subjects remained below the average range, except for peak years, the total mean verbal IQ score compared satisfactorily, even favorably, to verbal IQ scores reported in the literature. Program students appear to have more verbal ability than their reservation peers.

Nonverbal IQ scores, as expected from the literature, were higher than verbal scores. Four out of the six yearly means and the combined total mean fell within the average range. There were two peaks, at the second and sixth plus years, with declines between. The reasons for this patterning are not known.

Scores for total intelligence fell between the verbal and nonverbal IQ scores, and there was a much smaller range of differences between the mean scores for groups. The second year produced the peak score.

Possibly an unrecognized factor operated on all three areas of intelligence during the third year in the Program to reverse the initial trend for scores to increase with successive years. Perhaps 
this factor is similar to the crossover found in achievement test research.

The covariates tested had no significant effect on any of the IQ scores measured. In addition, number of nomes had no effect on verbal or nonverbal intelligence, but did have a highly significant negative effect on total IQ. It is not possible, however, to tell whether a lowered IQ resulted after placement in several homes, or whether an initially lower IQ led to more adjustment, school, or home problems, and thus to multiple placement.

Limitations of this Study

The primary limitation of this study was the sketchy and incomplete data available from the schools. More complete achievement and intelligence data would have made conclusions more certain and results more able to be generalized. Small N's for a few groups curtailed some analyses.

Another drawback was the fact that several different tests were given which raised a question as to the comparability and correlations between the tests. This was a particular problem with achievement tests.

An Ideal study would have involved a rather large number of subjects placed in the same grade, the same year, at about the same age, and all given the same achievement and intelligence tests at the same time annualiy for at least five years. Since it is not possible to so manipulate humans, this study should be accepted as not the ideal, but the best possible compromise with reality in a rather limited situation. 
Nevertheless, although the methodological limitations are apparent this study should not be discounted. The results reported herein are consistent with the literature, and therefore it can reasonably be predicted that an expanded study with the limitations controlled would have similar findings.

\section{Suggestions for Further Research}

This study has been, in essence, a pioneer project, and there are limitless possibilities for further research. A cast of doubt has been brought upon the benefits and accomplishments, at least in scholast1c fields, of the LDS Indian Placement Program. However, before definite conclusions should be drawn and changes made in the Program, more information is essential. Probably the most productive and enlightening study now would be an actual longttudinal study, including a control group of subjects remaining on the reservation. In addition, it would be most helpful to conduct, at the same time, a paired longitudinal study of a similar group of LDS Indian children who do not enroll in the Placement Program and are educated in their home schools. A thorough study of this nature would enable the covariate and adjustment factors mentioned here to be further detailed, and would better answer questions about crossover effect in intelligence and achievement. 
CHAPIER 6

\section{SUMMARY AND CONCLUSIONS}

The Indian Placement Program of the Church of Jesus Christ of Latter-day Saints takes Indian children as young as eight years old and places them in a supportive white foster home during the nine months of a school year, in hopes of bettering their chances for success in life. One of the primary goals of this Placement Program is the educational enrichment of the Indian children enrolled. This study, which originally set out to support and reinforce the Program, and demonstrate increased academic success among the enrolled Indian students, has concluded by instead raising questions as to whether or not any actual educational or academic benefits are accrued by the students.

A review of the literature on achievement and intelligence test results of Indian students in reservation and predominantly Indian schools was disheartening, and pointed out the great educational disadvantages Indians have in the past and do presently face. Indian students in most studies were years behind in all academic achievement areas. Also, they were greatly handicapped on Intelligence tests, particularly verbal tests. It was expected and hoped that Placement students would show great improvement over the subjects of these studies. 
In this study the school records of all Placement Program students in the Wasatch front area who have participated for five or more continuous years in the Program were examined. All available standardized achievement and intelligence test data were obtained for each student. It was anticipated that each year students participated in the Program would bring improved, or at least maintained, achievement, and that verbal intelligence would also improve with the increased exposure to the white culture that placement brings.

None of the expected results were obtained, and Instead a tendency for yearly declines was found on achievement scores in mathematics, reading, and language, probably the three subject areas most important for success in school. During their first year in the Program, Placement students were almost three tenths of a year behind, but by their sixth or later years in the Program they averaged nore than a year and four tenths behind in these three academic areas. Overall achievement for all students for all years in Program averaged almost a year below grade level expectations. Intelligence test results were no more encouraging. Scores began at first to improve with years in the Program, but generally after a peak at about the second year also began to decline. These results are disappointingly similar to the studies reviewed in the literature. The results do not support, but rather question the validity of the Placement Program.

There is growing concern among both whites and Indians over the Indian plight today. The need now to find something, some program 
or plan, that will give Indian children more help to overcome their current disadvantages is obvious. A good education would not cure all the Indians' problems, but would be a giant step on the way to a cure. Members of the LDS Church have special historical and religious reasons for their particular interest in helping the Indians. The Placement Program has been one major attempt at help, but, at least from the results of this study, the Program is not currently successful academically. Further study of this Program and possible ways of altering it for improved success is essential. Other ways that LDS people can help the Indian, particularly educationally, need to be explored and seriously considered. 
REFERENCES

The angry American Indian: Starting down the protest trail. Time, 1970, 25 (6), 14-20.

Arthur, G. An experience in testing Indian school children. Mental Hygiene, 1941, 25, 188-195.

Berry, B. The education of American Ind ians: A survey of the literature. U.S. Department of Health, Eacation, and Welfare, Office of Education, Bureau of Research, 1968.

Bishop, C.R. An evaluation of the scholastic achievement of selected Indian students attending elementary public schools in Utah. (Unpublished master's thesis, Brighom Young University) Provo, Utah, 1960.

Bishop, C.R. A history of the Indian Student Placement Program of the Church of Jesus Christ of Latter-day Saints. (Unpublished master's thesis, University of Utah), Salt Lake City, Utah, 1967.

Bryde, J.F. The Sioux Indian student: A study of scholastic failure and personality conflict. copyright by Rev. John Frances Bryde, S. J., 1966.

Coombs, L.M., Kron, R.E., Collister, E.G., \& Anderson, K.E. The Indian child goes to school: A study of interracial differences. United States Department of the Interior, Bureau of Indian Affairs, 1958.

Cowen, P.A. Testing Indian school pupils in the state of New York. Mental Hygiene, 1943, 27, 80-82.

Crump, B.L. The educability of Indian children in reservation schools. Durant, Oklahoma: Southeastern State Teachers College, 1932.

Cundick, B.P. Measures of intelligence on Southewest Indian students. The Journal of Social Psychology, 1970, 81, $151-156$.

Edington, E.D. Academic Achievement. Journal of American Indian Education, 1969,8 (3), 10-15.

Erickson, D.A. Failure in Navajo schooling. Parents' Magazine, 1970, XLV (9), 66-68+. 
Fitzgerald, J.A., \& Ludeman, W.W. The intelligence of Indian children. The Journal of Comparative Psychology, 1926, 6, 319-328.

Garth, T.R., Schuelke, N., \& Abell, W. The intelligence of mixed blood Indians. Journal of Applied Psychology, 1927, 1I, $268-275$.

Garth, T.R., Serafini, T.J., \& Dutton, D. The intelligence of full blood Indians. Journal of Applied Psychology, 1925, 2, 382-389.

Garth, T.R., Smith, H.W., \& Abell, W. A study of the intelligence and achievement of full-blood Indians. Journal of Applied Psychology, 1928, 12, 511-516.

Garth, T.R., \& Smith, O.D. The performance of full-blooded Indians on language and non-language intelligence tests. Journal of Abnormal and Social Psychology, 1937, 32, 376-381.

Goodenough, F.L. Racial differences in the intelligence of school children. Journal of Experimental Psychology, 1925, 2 , 388-397.

Hansen, H. C. Scholastic achievement of Indian pupils. Journal of Genetic Psychology, 1937, 50, 361-369.

Havighurst, R. J., Gunther, M.K., \& Pratt, I.E. Environment and the Draw-A-Man Test: The performance of Indian children. Journal of Abnormal and Social Psychology, 1944, 39, 419433 .

Havighurst, R.J., \& Hilkevitch, R.R. The intelligence of Indian children as measured by a performance scale. Journal of Abnormal and Social Psychology, 1944, 32, 419-433.

Howell, R.J., Evans, L., \& Downing, L.N. A comparison of test scores for the 16-17 year age group of Navajo Indians with standardization norms for the Wechsler Adult Intelligence Scale (Arizona and New Mexico). Journal of Social Psychology, $1958,47,355-359$.

Hunter, W.S., \& Sommermier, E. The relation of degree of Indian blood to score on the Otis Intelligence Test. The Journal of Comparative Psychology, 1922, 2 , 257-277.

Indian education--a national disgrace. Today's Education, 1970, 59 (3), $24-27$. 
Kelly, W.H. A study of southern Arizona school-age Indian children 1966-1967. Tucson, Arizona: Bureau of Ethnic Research, Department of Anthropology, University of Arizona, 1967.

Martin, M. An analysis of reading achievement of Navajo students. In W.W. Dick (Ed.), Report of the Annual Conference of the Co-ordinating Council for Research in Indian Education. Phoenix: Arizona State Department of Public Instruction, 1962.

Owens, C.S., \& Bass, W.P. The American Indian high school dropout in the Southwest. Alburquerque, N.M.: Southwestern Cooperative Educational Laboratory, 1969.

Peterson, S. How well are Indian children educated? Lawrence, Kansas: United States Indian Service, 1948.

Roessel, B.A., Jr. Handbook for Indian education. Los Angeles: Amerindian Publishing Co. (no date).

Rowe, E.C. Five hundred forty-seven white and two hundred sixtyeight Indian children tested by the Binet-Simon Tests. Pedagogical Seminary, 1914, 21, 454-468.

Townsend, I.D. Reading achievement of eleventh and twelfth grade Indian students. Journal of American Indian Education, 1963,1 (3), 9-10.

Tunley, R. The 50,000,000 acre ghetto. Seventeen, 1970, 28 (10), $222-223+$.

Zintz, M.V. The Indian research study: The adjustment of Indian and non-Indian children in the public schools of New Mexico. Alburquerque, New Mexico: The University of New Mexico, 1960. 


\title{
CHANGES IN SCHOLASTIC ACHIEVEMENT AND INTELLIGENCE \\ OF INDIAN CHILDREN ENROLIED IN A \\ FOSTER PLACEMENT PROGRAM
}

\author{
Linda Ouida Willson \\ Department of Psychology \\ M.S. Degree, April 1973
}

\begin{abstract}
This study investigated the long-term effects of involvement
\end{abstract} in the Indian Placement Program of the Church of Jesus Christ of Latter-day Saints on academic achievement and intelligence of Indian children. Data from standardized intelligence and achievement tests administered by the schools during the subjects' five or more years in the Program were collected. Expectations that achievement and intelligence scores would improve with successive years in the Program were not supported. Instead, math and language achlevement decreased significantly, and reading showed declining trends with successive years in Program. Intelligence scores peaked at second year in Program then tended to decline. Verbal intelligence did not increase.

Other factors were studied. The particular achievement test influenced scores. Beginning age and grade interacted with sex and years in Program to increase sex difference and decrease years in Program effect. Subjects placed in 1961 tended to achieve higher than subjects placed in later years. Number of homes lived in affected only total intelligence scores.

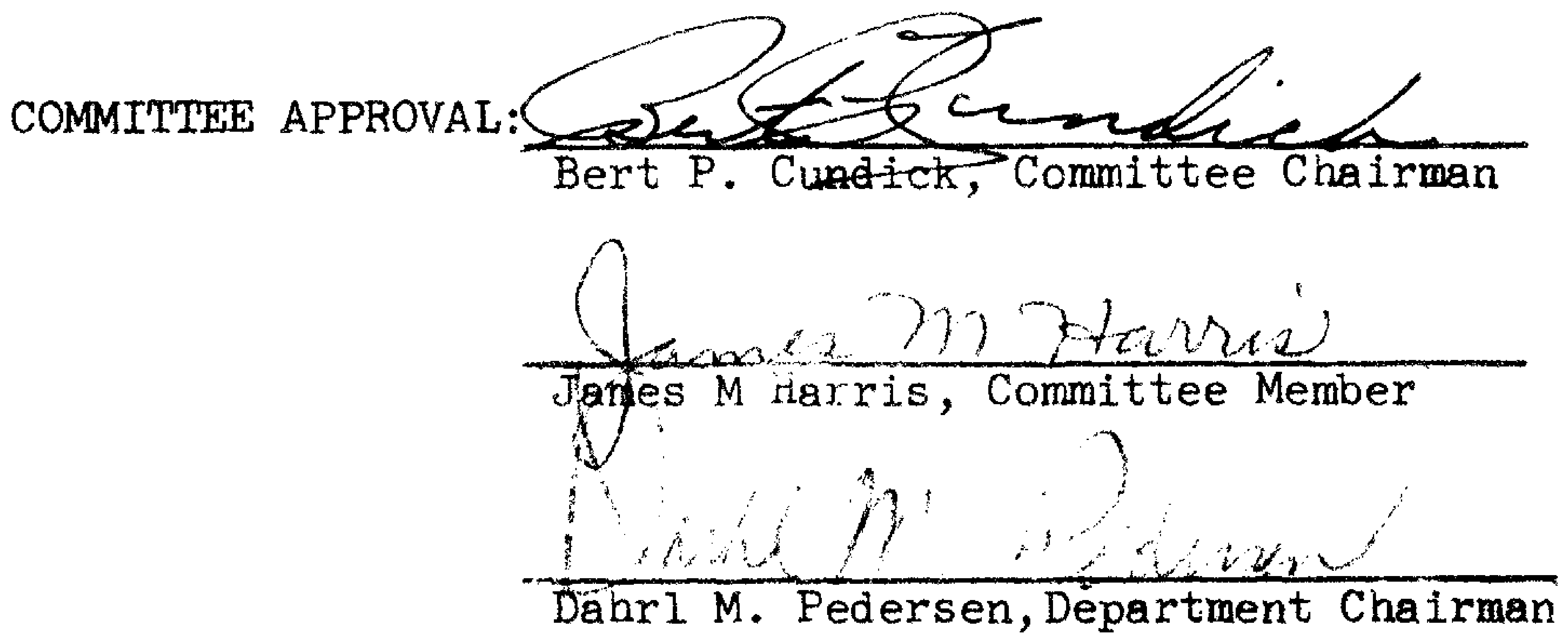

